Review Article:

\title{
The Accuracy of Myocardial Performance Index in the Diagnosis of Right Ventricular Dysfunction After Surgical Correction of Tetralogy of Fallot: A Narrative Review
}

\author{
Asadolah Tanasan $^{1}$ (D), Reza Shabanian ${ }^{2 *}$ (D) Minoo Dadkhah² ${ }^{\text {(D) }}$, Ehsan Mazloumi ${ }^{3}$ (i)
}

1. Department of Pediatrics, School of Medicine, Besat Hospital, Hamadan University of Medical Sciences, Hamadan, Iran.

2. Department of Pediatric Cardiology, School of Medicine, Children's Medical Center, Tehran University of Medical Sciences, Tehran, Iran.

3. Department of Biostatistics and Epidemiology, School of Health, Hamadan University of Medical Sciences, Hamadan, Iran.

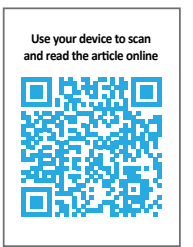

ditation Tanasan A, Shabanian R, Dadkhah M, Mazloumi E. The Accuracy of Myocardial Performance Index in the Diagnosis of Right Ventricular Dysfunction After Surgical Correction of Tetralogy of Fallot. Journal of Pediatrics Review. 2019; 7(3):161-168. http:// dx.doi.org/10.32598/jpr.7.3.161

doishttp://dx.doi.org/10.32598/jpr.7.3.161

\section{(c) (1) (8)}

Article info:

Received: 02 January 2018 First Revision: 11 August 2018

Accepted: 19 August 2018

Published: 01 July 2019
Keywords:

RV MPI,

Echocardiography, Tetralogy of Fallot, Right ventricular dysfunction

\begin{abstract}
A B S TR A C T
Context: Tetralogy of Fallot (TOF) is one of the most important congenital heart diseases that its prognosis can be improved by surgery. However, Right Ventricular (RV) function may be disrupted because of pulmonary regurgitation and other preoperative and intraoperative factors. Access to a simple and reproducible diagnostic index of RV function is important. Echocardiographic index of Right Ventricular Myocardial Performance (RVMPI) has been used as a simple and noninvasive method for the assessment of RV function.
\end{abstract}

Evidence Acquisition: This article review was conducted utilizing PubMed, Web of Science, Scopus and Google Scholar databases with the keywords of "Right Ventricle (RV)", "Myocardial Performance Index (MPI)", and "Tetralogy of Fallot (TOF) repair or correction".

Results: RVMPI as a non-geometric echocardiographic index was compared with other echocardiographic indices, QRS duration in ECG, Cardiac Magnetic Resonance (CMR) findings, and exercise capacity in the pediatric and adult studies.

Conclusions: This narrative review suggested that RVMPI, especially the tissue Doppler-derived has been used as a useful index of RV function in the follow-up of the repaired TOF patients. However, more research, including systematic reviews are necessary to determine the potential implication of RVMPI in the assessment of RV dysfunction.

* Corresponding Author:

Reza Shabanian, MD.

Address: Department of Pediatric Cardiology, School of Medicine, Children's Medical Center, Tehran University of Medical Sciences, Tehran, Iran Tel: +98 (813) 2640064

E-mail: rshabanian@yahoo.com 


\section{Context}

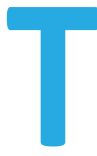

he evaluation of Right Ventricular (RV) myocardial function after the total correction of Tetralogy of Fallot (TOF) predicts early and late prognosis of the patients (1-3). Pulmonary Regurgitation (PR) is the most important prognostic factor that affects RV myocardial function and the late outcome after TOF correction (4). Progressive RV dysfunction is commonly associated with life-threatening arrhythmia and sudden death (2). Pulmonary Valve Replacement (PVR) is performed to avoid these complications at the right time (5).

Various diagnostic methods have been used in this regard, including electrocardiography, echocardiography, and magnetic resonance imaging. QRS duration in ECG has been investigated in several studies as a prognostic factor in the repaired TOF (rTOF) patients (6). The QRS duration of more than 180 ms was associated with lifethreatening dysrhythmia and sudden death (7). Cardiac Magnetic Resonance (CMR) imaging is widely used in the assessment of cardiac function. It is the gold standard method in the assessment of RV function in rTOF patients $(8,9)$. However, it is expensive and time-consuming compared to the echocardiographic methods.

Conventional echocardiography is used for the serial assessment of RV function and pulmonary regurgitation after rTOF (10). First described by Chuwa Tei, Myocardial Performance Index (MPI) is a dimensionless echocardiographic parameter of systolic and diastolic function (11). Tei index is calculated by IVCT+IVRT/ET or $a-b / b$ formula ( $a=$ closure opening time of AV valve; $b=e j e c t i o n$ time) in spectral Doppler echocardiography (12). Right Ventricle Myocardial Performance Index (RVMPI) as a global systolic and diastolic function is affected by pulmonary regurgitation and myocardial dysfunction $(13,14)$. The available data are controversial on the load dependency of the MPI (15-17).

MPI is affected by load and heart rate and disregards segmental function (18). However, several studies report that RVMPI could be used as a quantitative measure of RV performance $(19,20)$. As a simple nongeometric echocardiographic parameter, MPI was calculated in several studies to assess RV function after the surgical repair of TOF. Tei index is potentially a simple, reproducible, and readily available indicator of ventricular dysfunction. Nonetheless, the clinical applicability of RVMPI remains undiscovered (13).
We reviewed the application of MPI in rTOF patients compared to other modalities in addition to the impact of pulmonary regurgitation on this echocardiographic parameter.

\section{Evidence Acquisition}

The article review was performed utilizing PubMed, Web of Science, Scopus, and Google Scholar, with the following keywords: "myocardial Performance Index (MPI)", "Right Ventricle (RV)", "Tetralogy of Fallot (TOF) repair or correction". All studies in English from 1995 till the current time on TOF patients who had total correction with early or late postoperative echocardiographic evaluation were included, if they assessed RVMPI either by pulsed or tissue Doppler imaging (Table 1 ).

\section{Results}

\subsection{Comparing RV MPI with other echocardiographic indices}

RV MPI as a non-geometrical index can be used to assess right ventricular myocardial function (21-24). RVMPI is derived either by Pulsed Doppler (PD) or Tissue Doppler (TD) methods. Because of the special shape of RV, loading factors can affect some of the geometrical $\mathrm{RV}$ indices $(25,26)$. Although RVMPI is known as a nongeometrical index, PD-derived MPI might be affected by loading factors like the pulmonary regurgitation after TAP repair of TOF.

There is still debate in the similarity of PD- and TDderived MPI for the assessment of RV function. Saylan et al. found no difference between the rTOF and normal groups in PD-RVMPI $(0.13 \pm 0.03$ and $0.15 \pm 0.04, P=0.16)$. However, TD-RVMPI was statistically higher in patients in respect of RV dysfunction after surgery $(0.73 \pm 0.059$ and $0.51 \pm 0.034, \mathrm{P}<0.001$ ) (27). PD-MPI was partially influenced by changes in preload and heart rate, while TD-MPI was not affected (15).

Yasuoka et al. indicated that TD-RVMPI measurement is superior to the PD method to detect RV dysfunction in rTOF patients with PR (26). The RVMPI obtained by the PD method did not differ in rTOF and normal matched group $(0.30 \pm 0.12$ vs. $0.32 \pm 0.07$, the $P$ value was not significant). In contrast, the TD-RVMPI was significantly greater in rTOF $(0.48 \pm 0.07$ vs. $0.30 \pm 0.07, \mathrm{P}<0.0001)$. The possibility of simultaneous measurement of the isovolumetric and ejection times in the same cardiac cycle by the method of TD is considered as the advantage of TD-RVMPI over PD-RVMPI. Physiologic changes of more 
Table 1. Summary of reviewed articles

\begin{tabular}{|c|c|c|c|c|c|c|}
\hline Author & $\begin{array}{c}\text { Year of } \\
\text { Publication }\end{array}$ & Country & $\begin{array}{l}\text { Type of } \\
\text { Study }\end{array}$ & $\begin{array}{c}\text { Age, y } \\
\text { (Mean } \pm S D)\end{array}$ & $\begin{array}{c}\text { Technique of } \\
\text { MPI }\end{array}$ & Sample Size \\
\hline Abd El Rahman MY. & 2002 & Germany & Cross-sectional & $15.3 \pm 10.3$ & PD & $51 \mathrm{TOF}$ \\
\hline Yasuoka K. & 2004 & Japan & Cross-sectional & $6.3 \pm 2.2$ & PD and TD & $\begin{array}{l}15 \text { TOF vs. } 24 \text { age- } \\
\text { matched controls }\end{array}$ \\
\hline Norozi K. & 2006 & Germany & Cross-sectional & $30 \pm 8$ & PD & $\begin{array}{l}59 \text { TOF vs. } 52 \text { age- } \\
\text { matched controls }\end{array}$ \\
\hline Sachdev MS. & 2006 & India & Cross-sectional & $5 \pm 4.6$ & PD & 50 TOF \\
\hline Pilla CB. & 2007 & Brazil & Cross-sectional & $6.2 \pm 0.7$ & PD & $\begin{array}{l}35 \text { TOF vs. } 36 \text { age- } \\
\text { matched controls }\end{array}$ \\
\hline Cetin I. & 2009 & Turkey & Cross-sectional & $14.1 \pm 4.4$ & PD and TD & $\begin{array}{l}25 \text { TOF vs. } 29 \text { age- } \\
\text { matched controls }\end{array}$ \\
\hline Erdem S. & 2012 & Turkey & Cross-sectional & $7.9 \pm 4.4$ & PD and TD & $\begin{array}{l}57 \text { TOF vs. } 58 \text { age- } \\
\text { matched controls }\end{array}$ \\
\hline Saylan B. & 2012 & Turkey & Cross-sectional & $3.5 \pm 1.5$ & PD and TD & $\begin{array}{l}20 \text { TOF vs. } 30 \text { age- } \\
\text { matched }\end{array}$ \\
\hline Tanasan A. & 2012 & Iran & Cross-sectional & $6.4 \pm 4.1$ & PD & $\begin{array}{l}30 \text { TOF vs. } 32 \text { age- } \\
\text { matched controls }\end{array}$ \\
\hline Lu JC. & 2012 & US & Cross-sectional & $31 \pm 14.1$ & TD & $38 \mathrm{TOF}$ \\
\hline Tanasan A. & 2013 & Iran & Case series & $7.1 \pm 5.3$ & PD & $57 \mathrm{TOF}$ \\
\hline Promphan W. & 2014 & Thailand & Cross-sectional & $14 \pm 2$ & TD & 20 TOF \\
\hline
\end{tabular}

than $10 \%$ in the heart rate during PD examination will create less reliable results (28).

Both isovolumetric times were longer in rTOF, compared to the normal children (IVCT: $88 \pm 18$ vs. $62 \pm 23$ ms; IVRT: $46 \pm 11$ vs. $21 \pm 12 \mathrm{~ms}$; $\mathrm{P}<0.0001)$. Either intrinsic myocardial dysfunction or RV volume overload may contribute to prolonged IVRT and IVCT (29). Prolonged IVRT with decreased Ea revealed the delayed RV relaxation. Decreased Aa was in favor of restrictive RV filling. Prolonged IVCT (delayed systolic activation) in addition to decreased annular systolic descent suggested a systolic dysfunction.

All of the above-mentioned findings are in favor of diastolic/systolic dysfunction in TOF patients after the surgical repair. Moreover, the TD-RVMPI was not related to the PR degree and the residual RVOT obstruction. However, augmented PR may cause pseudonormalization of PD-RVMPI by prolonging the RV ejection time $(26,16)$. Higher RV filling pressures due to severe PR could cause pseudonormalization of this index. When the RV has a restrictive pattern in rTOF, there may be no correlation between RVMPI and RV ejection fraction $(30,31)$.

In a prospective study by Abd El Rahman et al. the measured PD-RVMPI in a group of rTOF at approximately 10 years post-surgery was paradoxically below the normal range. They claimed that the noncompliant right ventricle may shorten the IVRT; thus, resulting in low RVMPI. However, they found that the patients with severe PR had a prolongation of the IVRT, compared to the patients with mild to moderate PR. In other words, those repaired by transannular patch had a higher index than those repaired by homograft $(P<0.05)(32)$. It is difficult to interpret the RVMPI in cases with restrictive RV pattern.

In a similar study by Sachdev et al. the RVMPI in rTOF patients with restrictive RV physiology was paradoxically below the normal range $(0.15 \pm 0.06$ vs. $0.26 \pm 0.09$, $\mathrm{P}<0.001$ ) because of shortened isovolumetric relaxation time $(19.4 \pm 17$ vs. $39 \pm 30, P<0.05)$. The only independent determinant of restrictive RV pattern after surgical repair of TOF was the use of transannular patch $(33,34)$. In a cross-sectional observational analysis on 57 postoperative TOF patients, higher TD-RVMPI, higher RV dimensions, and volumes, and significantly lower RV Ejection Fraction (EF) were found, compared to a group of 58 aged-match controls ( $P<0.001$ for all parameters).

They also found a positive correlation between RV MPI and LV MPI ( $r=0.541, P<0.001)$ (24). Focusing on the diastolic function of patients following the repair of TOF, there was a correlation between the lateral mitral $E / E^{\prime}$ 
with tricuspid $E / E^{\prime}(r=0.46 ; P=0.008)$ and the right ventricular MPI ( $r=0.42 ; \mathrm{P}=0.01)$ (35).

In another study on 25 patients with a Mean \pm SD age of $14.1 \pm 4.4$ years who underwent primary repair of TOF, the TD-RVMPI ( $1.08 \pm 0.35$ vs. $0.58 \pm 0.11, P=0.0001)$ was higher and the Isovolumetric Acceleration rate (IVA) (3.1 \pm 0.7 vs. $5.4 \pm 1.0 \mathrm{~ms}, \mathrm{P}=0.0001$ ) was lower than the matched control group. Moreover, the correlations between PR degree and TD-RVMPI ( $r=0.7, P=0.0001)$, and IVA ( $r=-0.7, P=0.0001)$ were statistically significant.

They found that IVCT and IVRT increased due to delayed systolic activation and delayed right ventricular relaxation, respectively. The authors also believed that the age at the time of assessment after the surgery has an impact on the results of MPI (36). In assessing the Tei index in adults with operated congenital heart disease, 59 patients with surgically corrected TOF had greater RVMPI than 52 patients with operated left-to-right shunt defects (RVMPI: $0.37 \pm 0.1$ vs. $0.25 \pm 0.06 ; P<0.0001$ ) (37).

\subsection{Comparison of RV MPI with ECG findings and Car- diac Resynchronization Therapy (CRT)}

Although the majority of studies reported that the QRS duration of more than 180 ms was correlated with severe RV dysfunction, other studies suggested that it might be affected by the RV size and the PR severity (6, 38-40). We failed to find any correlation between the RVMPI and QRS duration in a group of patients after the total correction of TOF $(r=0.242, P=0.084)$. Our study limitations included the small sample size and the lack of tissue Doppler technique for MPI measurement.

We recognized that the QRS duration of greater than 160 ms was strongly correlated with severe PR (41). Moreover, the RVMPI did not differ in patients with and without right bundle branch block $(P>0.05)$. However, the electromechanical delay does not affect the RVMPI (37). Systolic RV function and RV filling were improved by RV-CRT that was reflected by decreased RVMPI and increased RV maximum $+\mathrm{dP} / \mathrm{dt}$, pulmonary artery velocity time integral, and the RV filling time. RVMPI was $0.30 \pm 0.21$ at baseline rhythm that declined to $0.20 \pm 0.16$ after RV-CRT $(P=0.006)$ (42).

\subsection{Comparison of RVMPI with Cardiac MRI (CMR) findings}

Several CMR guided studies were performed in children and adults with corrected TOF. In these studies, multiple CMR indices were quantified and compared with the echocardiographic indices like RVMPI (9, 4345). The measured CMR parameters were pulmonary regurgitant fraction, RV ejection fraction, RV end-diastolic volume, RV end-systolic volume and RV fractional area change (RV FAC). A few studies in the rTOF patients reveal that RVMPI is not correlated with the RV function and the severity of PR is measured by $\operatorname{CMR}(9,43)$. However, other studies demonstrated that RVMPI values were inversely correlated with the CMR-derived RVEF. RVMPI $>0.45$ had a sensitivity of $70 \%$ and a specificity of $89 \%$ in terms of RV dysfunction (44).

PD-RVMPI and TD-RVMPI (DTI) could reliably diagnose RV dysfunction (confirmed by $\mathrm{CMR}$ ), but surprisingly only the PD-RVMPI was diagnostic in the combined analysis ( $P=0.0001$ vs. 0.18 ) (44). Koca et al. failed to find any significant correlation between TD-RVMPI and the parameters derived by cardiac MR for the assessment of RV function in 31 repaired TOF. They argued that although TD-RVMPI was significantly longer in rTOF patients than the controls $(0.80 \pm 0.18$ vs. $0.60 \pm 0.11$, respectively, $\mathrm{P}=0.0001$ ), it was not correlated with the right ventricle function source from CMR (43). However, they concluded that RVMPI could be used in the longterm follow-up of the patients operated for TOF.

A negative linear correlation was found between MPI and MRI-derived RVEF by Schwerzmann et al. in a group of patients with rTOF ( $r=0.73$ ). RVMPI values of $>0.4$ and $<0.25$ were predictive of RVEF $<35 \%$, and $\geq 50 \%$, respectively (44). In addition to RVMPI, myocardial tissue velocities (Sa, Ea, Aa, Ea/Aa, E/Ea), TAPSE (Tricuspid annular plane systolic excursion), and 3DE-RV findings were proportional to using CMR reference ranges $(8,23,45,46)$.

\subsection{Comparison of RVMPI with exercise capacity}

There are a few studies comparing RV MPI values to exercise capacity after TOF repair. These studies were conducted in children and adults and revealed that RV MPI values were inversely correlated with exercise capacity $(13,21,24)$. Erdem et al. found a higher RVMPI and significantly lower exercise duration and lower maximum heart rate while exercising in patients with corrected TOF $(P<0.001)$ (24). Cheung reported that RVMPI was inversely correlated with exercise duration $(r=-0.45, P=0.013)$ and peak oxygen consumption ( $r=-0.56, P=0.001)$. Increased MPI was a reflection of reduced exercise capacity in the patients after TOF repair (13).

Pilla et al. investigated the Health-Related Quality of Life (HRQoL) in 35 successfully rTOF patients with 4.9 years of follow-up, and found a trend between RVMPI 
and poorer results in physical domain; however, it was not statistically significant $(P=0.06)(3)$. Lu et al. found no statistically significant relation between RVMPI and physical activity or the quality of life. However, RVMPI was trended with clinically important physical dysfunction (35).

\subsection{RVMPI in pediatric and adult corrected TOF studies}

Studies were available in both children and adults assessing RVMPI after the surgical correction of TOF. All of them stated in concordance that RVMPI value increases with RV dysfunction associated with PR. However, studies in the adult reported a rather weak trend of rising $(21,44)$. It was revealed that prolonged chest tube drainage and postoperative ventilation time were significantly correlated with increased RVMPI. Even the ICU stay and the need for inotrope assistance were correlated with this index, however, with less significance. Moreover, the serial measurement of RVMPI might be a useful adjunct to proceed with an intervention (23).

\subsection{Correlation between RVMPI and PR in pediatric and adult corrected TOF studies}

Although there are several studies on the pros and cons of correlation between the pulmonary regurgitation degree measured by PR index and RVMPI in rTOF, they are not similar in their method of RVMPI measurement (TD-RVMPI vs PD-RVMPI) and the degree of PR severity (mild vs. moderate and severe) $(3,21,47-52)$. Moreover, all of them considered a small sample size. The pulmonary regurgitation after TOF repair is significant; thus, some studies have quantified it by non-geometrical indices, such as PR index (PI time to diastolic time), diastolic and systolic time velocities integral ratio, and the PR pressure half time (9). Although studies suggested that RVMPI was independent of chronic loading condition and the degree of PR (37), the opposite effect in acute loading changes had been reported by other studies (47-52).

These studies suggested that the RVMPI was probably affected by the PR, especially when the PR severity was high. Moreover, the PD-RVMPI was much more affected than the TD-RVMPI. Norozi et al. argued that the surgical type of right ventricular outflow tract reconstruction and nonhomogeneous contraction had no adverse effects on the myocardial performance index (37).

Ibrahim $L$ found no relationship between the TDRVMPI and the degree of regurgitation ( $P=0.183$ ) (50). However, we found a strong correlation between the conventional derived RVMPI and the degree of PR. The RVMPI in patients with $P R i<70 \%$ was $0.42 \pm 0.13$, compared to $0.24 \pm 0.1$ in the patients with $\mathrm{PRi} \geq 70 \%$ $(P<0.05)$. Another limitation of the latter study was the inclusion of patients with valved transannular patch repair that significantly impacts the degree of pulmonary regurgitation (10).

\section{Conclusions}

Although the available data are controversial on the load dependency of MPI, it is a noninvasive, feasible and reproducible method for the serial assessment of $\mathrm{RV}$ function. There is also some limitation in its clinical and functional implication in rTOF patients because of RVMPI pseudonormalization in cases with severe PR and restrictive RV patterns. Further investigations with larger sample sizes and a systematic review method are necessary to evaluate the potential applicability of RVMPI in the assessment of RV function.

\section{Ethical Considerations}

\section{Compliance with ethical guidelines}

There is no ethical principle to be considered doing this research.

Funding

This research did not receive any specific grant from funding agencies in the public, commercial, or not-forprofit sectors.

\section{Authors contributions}

Writing-review and editing, visualization: Reza Shabnian; Conceptualization: Asadolah Tanasan; Writingoriginal draft: Minoo Dadkhah; Writing-original draft and software: Ehsan Mazloumi; and supervision: Reza Shabnian, Asadolah Tanasan.

\section{Conflict of interest}

The authors declared no conflict of interest.

\section{Acknowledgements}

We thank colleagues at the Clinical Research Development Center of Hamadan Besat Hospital who provided their insight and expertise that greatly assisted the research. 


\section{References}

1. Gatzoulis MA, Clark AL, Cullen S, Newman CG, Redington AN. Right ventricular diastolic function 15 to 35 years after repair of tetralogy of Fallot. Circulation. 1995; 91(6):177581. [DOI:10.1161/01.CIR.91.6.1775] [PMID]

2. Ho KW, Tan RS, Wong KY, Tan TH, Shankar S, Le Tan J. Late complications following tetralogy of Fallot repair: The need for long-term follow-up. Annals-Academy of Medicine Singapore. 2007; 36(11):947-53. [PMID]

3. Pilla CB, Pereira CA, Fin AV, Aquino FV, Botta A, DalleMulle $L$, et al. Health-related quality of life and right ventricular function in the midterm follow-upassessment after tetralogy of Fallot repair. Pediatric Cardiology. 2008; 29(2):40915. [DOI:10.1007/s00246-007-9145-4] [PMID]

4. Frigiola A, Redington A, Cullen S, Vogel M. Pulmonary regurgitation is an important determinant of right ventricular contractile dysfunction in patients with surgically repaired tetralogy of Fallot. Circulation. 2004; 110(11 suppl.1):II153-7. [DOI:10.1161/01.CIR.0000138397.60956.c2]

5. Moradian M, Momeni N, Ghadrdoost B, Mortezaeian H, Khorgami MR. Echocardiographic evaluation of right ventricular function after pulmonary valve replacement in patients with tetralogy of Fallot. Iranian Heart Journal. 2017; 17(4):42-8.

6. Gatzoulis M, Till J, Somerville J, Redington AN. Mechanoelectrical interaction in tetralogy of Fallot. QRS prolongation relates to right ventricular size and predicts malignant ventricular arrhythmias and sudden death. Circulation. 1995; 92(2):231-7. [PMID]

7. Silka MJ, Hardy BG, Menashe VD, Morris CD. A populationbased prospective evaluation of risk of sudden cardiac death after operation for common congenital heart defects. Journal of the American College of Cardiology. 1998; 32(1):245-51. [DOI:10.1016/S0735-1097(98)00187-9]

8. Hamilton-Craig CR, Stedman K, Maxwell R, Anderson B, Stanton T, Chan J, et al. Accuracy of quantitative echocardiographic measures of right ventricular function as compared to cardiovascular magnetic resonance. IJC Heart \& Vasculature. 2016; 12:38-44. [DOI:10.1016/j.ijcha.2016.05.007] [PMID] [PMCID]

9. Mercer-Rosa L, Yang W, Kutty S, Rychik J, Fogel M, Goldmuntz E. Quantifying pulmonary regurgitation and right ventricular function in surgically repaired tetralogy of Fallot: A comparative analysis of echocardiography and magnetic resonance imaging. Circulation: Cardiovascular Imaging. 2012; 5(5):637-43. [DOI:10.1161/CIRCIMAGING.112.972588] [PMID] [PMCID]

10. Tanasan A, Zanjani KS, Kocharian A, Kiani A, Navabi MA Right ventricular myocardial tissue velocities, myocardial performance index, and tricuspid annular plane systolic excursion in totally corrected tetralogy of Fallot patients. The Journal of Tehran University Heart Center. 2012; 7(4):1603. [PMCID]
11. Tei C, Ling LH, Hodge DO, Bailey KR, Oh JK, Rodeheffer RJ, et al. New index of combined systolic and diastolic myocardial performance: a simple and reproducible measure of cardiac function--a study in normals and dilated cardiomyopathy. Journal of Cardiology. 1995; 26(6):357-66. [PMID]

12. Eidem BW, O'Leary PW, Tei C, Seward JB. Usefulness of the myocardial performance index for assessing right ventricular function in congenital heart disease. The American Journal of Cardiology. 2000; 86(6):654-8. [DOI:10.1016/ S0002-9149(00)01047-X]

13. Cheung EW, Lam WW, Cheung SC, Cheung YF. Functional implications of the right ventricular myocardial performance index in patients after surgical repair of tetralogy of Fallot. Heart and Vessels. 2008; 23(2):112-7. [DOI:10.1007/ s00380-007-1016-7] [PMID]

14. Eidem BW, Tei C, O'Leary PW, Cetta F, Seward JB. Nongeometric quantitative assessment of right and left ventricular function: Myocardial performance index in normal children and patients with Ebstein anomaly. Journal of the American Society of Echocardiography. 1998; 11(9):84956. [DOI:10.1016/S0894-7317(98)70004-5]

15. Ozdemir K, Balci S, Duzenli MA, Can I, Yazici M, Aygul N, et al. Effect of preload and heart rate on the Doppler and tissue Doppler derived myocardial performance index. Clinical Cardiology. 2007; 30(7):342-8. [DOI:10.1002/clc.20109] [PMID]

16. Kiani A, Shabanian R, Seifirad S, Heidari-Bateni G, Rekabi M, Shahbaznejad $L$, et al. The impact of preload alteration on the myocardial performance index through implementing positive end expiratory pressure. Echocardiography. 2012; 29(8):9005. [DOI:10.1111/j.1540-8175.2012.01742.x] [PMID]

17. Shabanian R, Aboozari M, Kiani A, Seifirad S, Zamani G, Nahalimoghaddam $A$, et al. Myocardial performance index and atrial ejection force in patients with Duchenne's muscular dystrophy. Echocardiography. 2011; 28(10):1088-94. [DOI:10.1111/j.1540-8175.2011.01515.x] [PMID]

18. Tamborini G, Marsan NA, Gripari P, Maffessanti F, Brusoni $D$, Muratori $M$, et al. Reference values for right ventricular volumes and ejection fraction with real time three dimensional echocardiography: Evaluation in a large series of normal subjects. Journal of the American Society of Echocardiography. 2010; 23(2):109-15. [DOI:10.1016/j. echo.2009.11.026] [PMID]

19. Tei C, Dujardin KS, Hodge DO, Bailey KR, McGoon MD, Tajik AJ, et al. Doppler echocardiographic index for assessment of global right ventricular function. Journal of the American Society of Echocardiography. 1996; 9(6):838-47. [DOI:10.1016/S0894-7317(96)90476-9]

20. Ozdemir K, Altunkeser BB, Içli A, Ozdil H, Gök H. New parameters in identification of right ventricular myocardial infarction and proximalright coronary artery lesion. Chest. 2003; 124(1):219-26. [DOI:10.1378/chest.124.1.219]

21. D’Andrea A, Caso P, Sarubbi B, Russo M, Ascione L, Scherillo $M$, et al. Right ventricular myocardial dysfunction in adult patients late after repair of tetralogy of Fallot. International 
Journal of Cardiology. 2004; 94(2):213-20. [DOI:10.1016/j. ijcard.2003.04.033] [PMID]

22. Miller D, Farah MG, Liner A, Fox K, Schluchter M, Hoit BD. The relation between quantitative right ventricular ejection fraction and indices of tricuspid annular motion and myocardial performance. Journal of the American Society of Echocardiography. 2004; 17(5):443-7. [DOI:10.1016/j. echo.2004.01.010] [PMID]

23. Song B, Qi Q, Liu R, Xing W, Tang H, Li Y. Clinical value of Tei index in pediatric patients with repaired tetralogy of Fallot. International Journal of Clinical and Experimental Medicine. 2015; 8(5):7971-6. [PMID] [PMCID]

24. Erdem S, Özbarlas N, Küçükosmanoglu O, Poyrazoglu H, Salih OK. Mid-term results of patients following total surgical correction of tetralogy of Fallot. The Turkish Journal of Pediatrics. 2012; 54(4):393-402. [PMID]

25. Nair KKM, Ganapathi S, Sasidharan B, Thajudeen A, Pillai HS, Tharakan J, et al. Asymptomatic right ventricular dysfunction in surgically repaired adult tetralogy of Fallot patients. Annals of Pediatric Cardiology. 2013; 6(1):24-8. [DOI:10.4103/0974-2069.107229] [PMID] [PMCID]

26. Yasuoka K, Harada K, Toyono M, Tamura M, Yamamoto F. Tei index determined by tissue Doppler imaging in patients with pulmonary regurgitation after repair of tetralogy of Fallot. Pediatric Cardiology. 2004; 25(2):131-6. [DOI:10.1007/s00246-003-0514-3] [PMID]

27. Şaylan B, Çevik A, Tavlı V. Relationship between ventricular function assessed by tissue Doppler imaging and exercise capacity in patients after repair of tetralogy of Fallot: An observational study. Anatolian Journal of Cardiology. 2012; 12(6):490-7. [PMID]

28. Harada K, Takahashi Y, Shiota T, Suzuki T, Tamura M, Ito T, et al. Effect of heart rate on left ventricular diastolic filling patterns assessed by Doppler echocardiography in normal infants. The American Journal of Cardiology. 1995; 76(8):634-6. [DOI:10.1016/S0002-9149(99)80175-1]

29. Yu CM, Sanderson JE, Chan S, Yeung L, Hung YT, Woo KS. Right ventricular diastolic dysfunction in heart failure. Circulation. 1996; 93(8):1509-14. [DOI:10.1161/01. CIR.93.8.1509] [PMID]

30. Selly JB, Iriart X, Roubertie F, Mauriat P, Marek J, Guilhon $E$, et al. Multivariable assessment of the right ventricle by echocardiography in patients with repaired tetralogy of Fallot undergoing pulmonary valve replacement: A comparative study with magnetic resonance imaging. Archives of Cardiovascular Diseases. 2015; 108(1):5-15. [DOI:10.1016/j.acvd.2014.07.054] [PMID]

31. Rudski LG, Lai WW, Afilalo J, Hua L, Handschumacher MD, Chandrasekaran K, et al. Guidelines for the echocardiographic assessment of the right heart in adults: A report from the American Society of Echocardiography endorsed by the European Association of Echocardiography, a registered branch of the European Society of Cardiology, and the Canadian Society of Echocardiography. Journal of the
American Society of Echocardiography. 2010; 23(7):685713. [DOI:10.1016/j.echo.2010.05.010] [PMID]

32. El Rahman MA, Abdul-Khaliq $\mathrm{H}$, Vogel $\mathrm{M}$, Alexi-Meskischvili $V$, Gutberlet $M$, Hetzer R, et al. Value of the new Dopplerderived myocardial performance index for the evaluation of right and left ventricular function following repair of tetralogy of Fallot. Pediatric Cardiology. 2002; 23(5):502-7. [DOI:10.1007/s00246-002-1469-5] [PMID]

33. Sachdev MS, Bhagyavathy A, Varghese R, Coelho R, Kumar RS. Right ventricular diastolic function after repair of tetralogy of Fallot. Pediatric Cardiology. 2006; 27(2):250-5. [DOI:10.1007/s00246-005-1186-y] [PMID]

34. Norgård G, Gatzoulis MA, Moraes F, Lincoln C, Shore DF, Shinebourne EA, et al. Relationship between type of outflow tract repair and postoperative right ventriculardiastolic physiology in tetralogy of Fallot: Implications for long-term outcome. Circulation. 1996; 94(12):3276-80. [DOI:10.1161/01.CIR.94.12.3276] [PMID]

35. Lu JC, Cotts TB, Dorfman AL. Diastolic function and patientreported quality of life for adolescents and adults with repaired tetralogy of Fallot: A tissue Doppler study. Pediatric Cardiology. 2012; 33(4):618-24. [DOI:10.1007/s00246012-0189-8] [PMID]

36. Cetin I, Tokel K, Varan B, Orün U, Aşlamaci S. Evaluation of right ventricular function by using tissue Doppler imaging in patientsafter repair of tetralogy of Fallot. Echocardiography. 2009; 26(8):950-7. [DOI:10.1111/j.15408175.2009.00918.x] [PMID]

37. Norozi K, Buchhorn R, Bartmus D, Alpers V, Arnhold JO, Schoof $S$, et al. Elevated brain natriuretic peptide and reduced exercise capacity in adult patientsoperated on for tetralogy of Fallot is due to biventricular dysfunction as determined by the myocardial performance index. The American Journal of Cardiology. 2006; 97(9):1377-82. [DOI:10.1016/j.amjcard.2005.11.057] [PMID]

38. Rosing DA, Borer JS, Kent KM, Maron BJ, Seides SF, Morrow $A G$, et al. Long-term hemodynamic and electrocardiographic assessment following operative repair of tetralogy of Fallot. Circulation. 1978; 58(3 Pt 2):I209-17. [PMID]

39. Murphy JG, Gersh BJ, Mair DD, Fuster V, McGoon MD, IIstrup DM, et al. Long-term outcome in patients undergoing surgical repair of tetralogy of Fallot. New England Journal of Medicine. 1993; 329(9):593-9. [DOI:10.1056/ NEJM199308263290901] [PMID]

40. Garson A, Nihill MR, Mcnamara DG, Cooley DA. Status of the adult and adolescent after repair of tetralogy of Fallot. Circulation. 1979; 59(6):1232-40. [DOI:10.1161/01. CIR.59.6.1232]

41. Tanasan A, Kocharian A, Zanjani KS, Payravian FK, Torabian S. Correlation between QRS duration, pulmonary insufficiency and right ventricle performance in totally corrected tetralogy of Fallot. Iranian Journal of Pediatrics. 2013; 23(5):593-6. [PMID] [PMCID] 
42. Janoušek J, Kovanda J, Ložek M, Tomek V, Vojtovič P, Gebauer $\mathrm{R}$, et al. Pulmonary right ventricular resynchronization in congenital heart disease: Acute improvement in right ventricular mechanics and contraction efficiency. Circulation: Cardiovascular Imaging. 2017; 10(9):pii:e006424. [DOI: 10.1161/CIRCIMAGING.117.006424] [PMID]

43. Koca B, Öztunç F, Eroğlu AG, Gökalp S, Dursun M, Yilmaz R. Evaluation of right ventricular function in patients with tetralogy of Fallot using the myocardial performance index and isovolumic acceleration: A comparison with cardiac magnetic resonance imaging. Cardiology in the Young. 2014; 24(3):422-9. [DOI:10.1017/S1047951113000504] [PMID]

44. Schwerzmann M, Samman AM, Salehian O, Holm J, Provost $\mathrm{Y}$, Webb GD, et al. Comparison of echocardiographic and cardiac magnetic resonance imaging for assessing right ventricular function in adults with repaired tetralogy of Fallot. The American Journal of Cardiology. 2007; 99(11):15937. [DOI:10.1016/j.amjcard.2007.01.035] [PMID]

45. D’Anna C, Caputi A, Natali B, Leonardi B, Secinaro A, Rinelli $G$, et al. Improving the role of echocardiography in studying the right ventricle of repaired tetralogy of Fallot patients: Comparison with cardiac magnetic resonance. The International Journal of Cardiovascular Imaging. 2018; 34(3):399-406. [DOI:10.1007/s10554-017-1249-1] [PMID]

46. Pietrzak R, Werner B. Right ventricular function assessment using tissue Doppler imaging and speckle tracking echocardiography. Journal of Ultrasonography. 2014; 14(58):32838. [DOI:10.15557/JoU.2014.0033] [PMID] [PMCID]

47. Cheung MM, Smallhorn JF, Redington AN, Vogel M. The effects of changes in loading conditions and modulation of inotropic state on the myocardial performance index: Comparison with conductance catheter measurements. European Heart Journal. 2004; 25(24):2238-42. [DOI:10.1016/j. ehj.2004.07.034] [PMID]

48. Koga S, Ikeda S, Matsunaga K, Naito T, Miyahara Y, Taura K, et al. Influence of hemodialysis on echocardiographic Doppler indices of the left ventricle: Changes in parameters of systolic and diastolic function and Tei index. Clinical Nephrology. 2003; 59(3):180-5. [DOI:10.5414/CNP59180] [PMID]

49. Voon WC, Su HM, Yen HW, Lin TH, Lai WT, Sheu SH. Left ventricular Tei index: Comparison between flow and tissue Doppler analyses. Echocardiography. 2005; 22(9):730-5. [DOI:10.1111/j.1540-8175.2005.00126.x] [PMID]

50. El Rahman MA, Abdul-Khaliq H, Vogel M, Alexi-Meskishvili $\mathrm{V}$, Gutberlet $\mathrm{M}$, Lange PE. Relation between right ventricular enlargement, QRS duration, and right ventricular function in patients with tetralogy of Fallot and pulmonary regurgitation after surgical repair. Heart. 2000; 84(4):416-20. [DOI:10.1136/heart.84.4.416] [PMID] [PMCID]

51. Renella P, Aboulhosn J, Lohan DG, Jonnala P, Finn JP, Satou $\mathrm{GM}$, et al. Two dimensional and Doppler echocardiography reliably predict severe pulmonary regurgitation as quantified by cardiac magnetic resonance. Journal of the
American Society of Echocardiography. 2010; 23(8):880-6. [DOI:10.1016/j.echo.2010.05.019] [PMID]

52. Promphan $\mathrm{W}$, Wonglikhitpanya $\mathrm{T}$, Katanyuwong $\mathrm{P}$, Siripornpitak S. A comparative study: Right ventricular assessment in post-repaired tetralogy of Fallot patients by echocardiogram with cardiac magnetic resonance imaging. Journal of The Medical Association of Thailand. 2014; 97(6):232-8. [PMID] 